\title{
OBITUARY
}

\section{ALEXANDER CHRISTIE REID}

Alexander Christie Reid died in Edinburgh while on holiday on August 20, 1950. Born in 1877 in Dundee, the son of the Rev. Alexander Reid, he was educated at Dundee High School and proceeded to Aberdeen University where he obtained the degrees of M.A. and B.Sc. in 1897. Turning to medicine he graduated M.B. (Hons.) in 1902, and M.I). (Hons.) in 1905. He took the

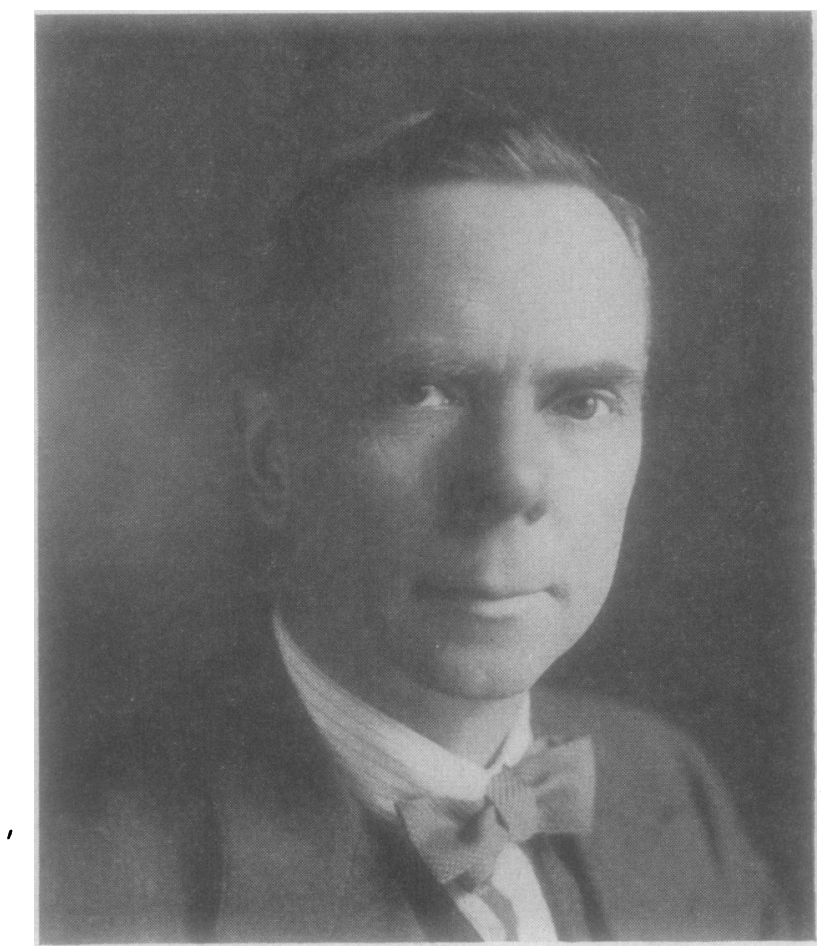

ALEXANDER CHRISTIE REID

post of House Surgeon to the West Norfolk and King's Lynn Hospital, and afterwards went into general practice, first in Rotherham, where he became interested in coal-miners nystagmus, and then in Nottingham. He was appointed Honorary Assistant Surgeon to the Nottingham and Midland Eye Infirmary in 1909, and full Honorary Surgeon in 1919, having meanwhile obtained the Diploma in Ophthalmology of Oxford in 1913, He was also Honorary Ophthalmic Surgeon to the Mansfield and Worksop Hospitals, and 
Adviser in Ophthalmology to the Kesteven County Council. Reid served in the R.A.M.C. in the great war, when he was mentioned in despatches; he retired from practice in 1947. His publications include "Miners' Nystagmus" (Brain, 1906, 29, 363), “On Nystagmus" (Ophthalmic Review, 1908, 27, 165), and "The Problem of the Hypermetropic Miner" (British Journal of Ophthalmology, 1943, 27, 110).

A keen church worker and for many years an Elder of his church and Session Clerk, he originally hoped to become a medical missionary but was rejected on medical grounds. He was known to his colleagues as a man of the highest integrity, who carried out his work with thoroughness and efficiency; his handwriting showed the neatness and good discipline of an orderly mind; he was never ruffled by circumstances and always ready to help and encourage his juniors. In 1911 he married Ellen, eldest daughter of the Rev. J. C. Grant, and to her and to his son and four daughters our deepest sympathy is extended.

\section{MARGARET RANKEN}

THE death of Miss Ranken after a short illness was briefly announced in last month's number of the Journal, but it now seems fitting to recall the prominent place which she occupied in ophthalmology. Her work as surgeon-in-charge of the orthoptic department of Sunderland Eye Infirmary has already received high praise. Having successfully organized the training of orthoptists in that institution, she was able to make many constructive suggestions at the Orthoptic Board, whose meetings she regularly attended in London. Her surgical skill in the treatment of squint was enhanced by her familiarity with the physiology of binocular vision.

Miss Ranken was appointed ophthalmic surgeon to the Ingham Infirmary, South Shields, a few years ago, having previously held the post of ophthalmic surgeon to Durham County Hospital. Her early training was varied and thorough. After graduating M.B. from the University of Durham in 1924, she did more than 20 years' work at the Victoria Infirmary, Newcastle-upon-Tyne, as house surgeon, refractionist, registrar, and associate surgeon.

Ophthalmology was far from being Miss Ranken's sole interest. She found time to play an active part in the Medical Women's Federation, and was formerly president of the Sunderland branch of the Soroptimists. She will be remembered not only for her professional achievements, but also because she was a pleasant companion on visits to other clinics, a loyal colleague, and a surgeon whose patience and gentleness of touch made children readily entrust themselves to her care. 